\title{
Studies towards the development of an ethanol sensor
}

\author{
A S N MURTHY*,1 and JYOTSNA RIKHIE ${ }^{2}$ \\ ${ }^{1}$ Tata Energy Research Institute, Darbari Seth Block, Habitat Place, \\ Lodhi Road, New Delhi 110 003, India \\ ${ }^{2}$ Department of Chemistry, Indian Institute of Technology, \\ New Delhi 110016 , India \\ e-mail: asmurthy@teri.res.in
}

MS received 14 May 1999; revised 4 August 1999

\begin{abstract}
An amperometric biosensor for ethanol is described. The sensor uses benzoquinone and ferrocene carboxylic acid as mediators for electron transfer between a quinoprotein, alcohol dehydrogenase and an edge plane pyrolytic graphite electrode. A linear current response proportional to ethanol concentration is observed in the range $1-10 \mathrm{mM}$.
\end{abstract}

Keywords. Benzoquinone; sensor; alcohol dehydrogenase; cyclic voltammetry.

\section{Introduction}

Biosensors based on $\mathrm{NAD}^{+}$and $\mathrm{NADP}^{+}$dehydogenases have attracted considerable attention because of their ubiquitous nature and large number ${ }^{1}$. While the cofactors, $\mathrm{NAD}^{+}$and $\mathrm{NADP}^{+}$aid in the enzymatic oxidation of the substrate, the direct oxidation of reduced NADH cannot be accomplished at low potentials without the help of mediators. In addition to those that use $\mathrm{NAD}(\mathrm{P})^{+}$as cosubstrates, there are a few dehydrogenases, termed quinoproteins ${ }^{2}$, which contain the prosthetic group 2,7,9-tricarboxy-1H-pyrrolo (2,3-f)-quinoline-4,5 dione (PQQ).<smiles>[H][Y]1=C2C=C(C(=O)O)N=C2C(=O)C(=O)C2=C1C(C(=O)O)C(C(=O)O)C2</smiles>

An important property of these enzymes is that they do not require $\mathrm{NAD}^{+}$participation but use artificial electron acceptors ${ }^{2,3}$. Davis et $a l^{4}$ have studied the reaction of the

*For correspondence 
quinoprotein, alcohol dehydrogenase (ADH) using N,N,N', $N^{\prime}$-tetramethyl-4phenylenediamine (TMPD) as an electron acceptor in a biofuel cell with methanol as substrate and this has provided a sensitive method for the detection of primary alcohols. Cass $e t a l^{5}$ have suggested that ferricinium ion functions as a good electron acceptor at $p \mathrm{H} 10.5$.

This paper reports cyclic voltammetric investigations of mediators such as ferrocene carboxylic acid (FCA) and p-benzoquinone (BQ) in the presence of alcohol dehydrogenase $(\mathrm{ADH})$ and a typical substrate ethanol at an edge plane pyrolytic graphite (EPG) electrode. Murthy and Sharma ${ }^{6}$ have recently shown BQ to be an efficient mediator, comparable to FCA in the development of sensors for a variety of substrates. The second order rate constant, for the reaction between the enzyme and the mediator at the optimum $p \mathrm{H} 10.5$ for the oxidation of ethanol has been estimated. Sensor characteristics for ethanol have been evaluated in solution and at an EPG electrode on which $\mathrm{ADH}$ and BA were immobilized in polypyrrole (PPy) matrix.

\section{Materials and methods}

$\mathrm{ADH}$ (ADH from horse liver, 1 ea $=400$ units, no $\mathrm{EC}$ number ${ }^{7}$, and FCA were procured from Aldrich and used as received. Ethanol (HPLC grade, E. Merck, Germany) and pyrrole (Sisco Research Laboratories, Mumbai, India) were distilled before use. Benzoquinone (Aldrich) was recrystallized twice from hot solutions of $n$-hexane. Double distilled water was used for making a $0.2 \mathrm{M}$ phosphate buffer. The enzyme solutions in buffer were deoxygenated by purging with $\mathrm{N}_{2}$ for atleast 30 min prior to use to prevent any competitive oxidation by dissolved oxygen.

Cyclic voltammetry experiments using BAS voltammograph (CV-27) and an X-Y-t recorder were performed in a conventional three electrode electrochemical cell having a working volume of $5 \mathrm{ml}$. An EPG electrode (area $0.122 \mathrm{~cm}^{2}$ ) supplied by LeCarbone Lorraine, France and polished with 600 grit $\mathrm{SiC}$ paper and $1 \mu \mathrm{m}$ diamond paste served as the working electrode. The counter electrode was a Pt wire. All potentials were referred to the $\mathrm{Ag} / \mathrm{AgCl}$ reference electrode.

\subsection{Electrochemical preparation of PPy membrane containing $A D H$ and $B Q$}

A PPy membrane was prepared in the presence of $\mathrm{ADH}$ and $\mathrm{BQ}$ by applying a potential of $1.0 \mathrm{~V}$ (versus $\mathrm{Ag} / \mathrm{AgCl}$ reference electrode) to an EPG electrode in a solution containing pyrrole $(0.1 \mathrm{M}), \mathrm{BQ}(0.1 \mathrm{mM})$ and $\mathrm{ADH}\left(15 \mathrm{mg} \mathrm{m}^{-1}\right)$. The electrolyte solution was $0.1 \mathrm{M}$ potassium chloride solution deoxygenated before electropolymerization. The polymerization was continued until a charge of $1 \mathrm{C} \mathrm{cm}^{-2}$ was accumulated. This was followed by thorough washing of the electrode with phosphate buffer ${ }^{8}$.

\section{Results and discussion}

The cyclic voltammogram of BQ at the EPG electrode in the presence of ADH is shown in figure 1a. BQ is known to adsorb on to EPG electrode. The electrochemistry of $B Q$ so adsorbed, however, is stable for hours and is the same as in solution. Sensor configurations with adsorbed mediators and immobilized enzymes are known in the literature (for example, the archetypal glucose sensor with ferrocene mediator ${ }^{1}$ ). Upon the addition of ethanol, a large catalytic current flows (figure $1 \mathrm{~b}$ ) which is indicative of the 


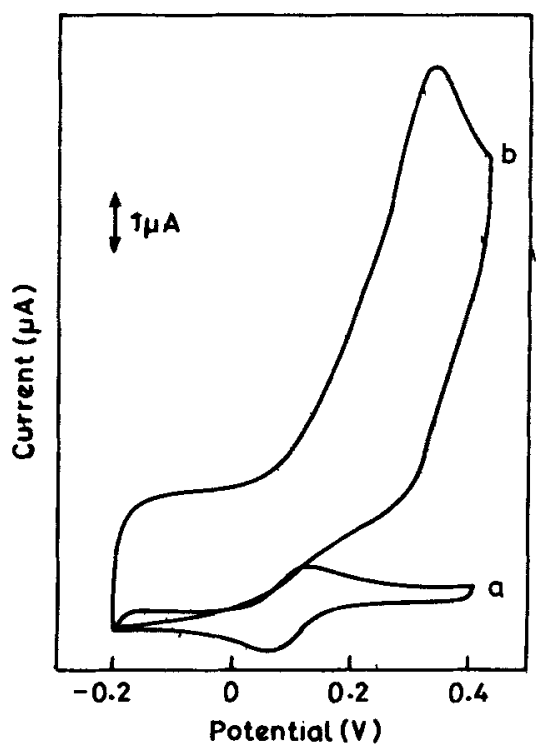

Figure 1. (a) Cyclic voltammogram of $1 \mathrm{mM}$ BQ at an EPG electrode in the presence of $1 \mu \mathrm{M} \mathrm{ADH}$. (b) As in (a) with $6 \mathrm{mM}$ ethanol in $0.1 \mathrm{M} \mathrm{NaOH}$-borax buffer $p \mathrm{H} 10 \cdot 5$, scan speed $5 \mathrm{mVs}^{-1}$.

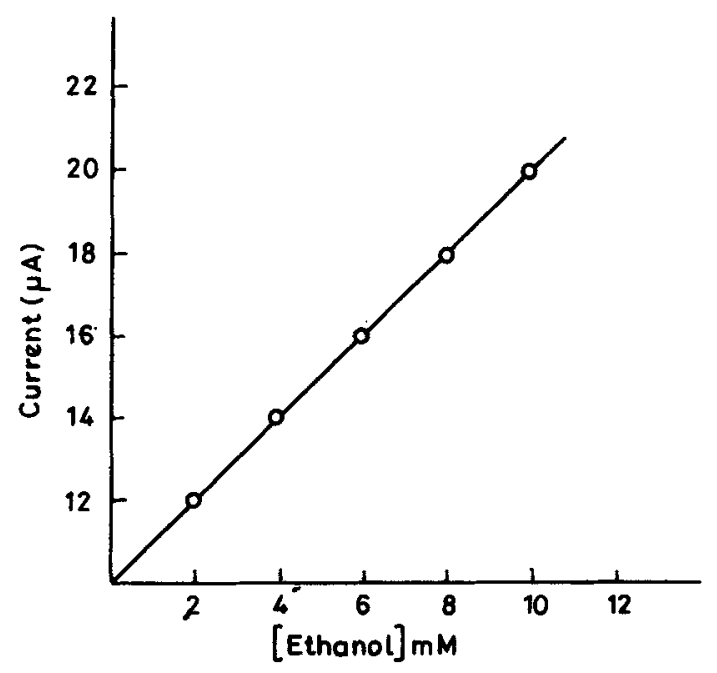

Figure 2. Variation of catalytic current with concentration of ethanol.

enzyme catalyzed oxidation of ethanol electrochemically coupled to $B Q$. The overall reaction catalyzed by the enzyme is as given below.

$$
\mathrm{C}_{2} \mathrm{H}_{5} \mathrm{OH}+\text { benzoquinone } \stackrel{\mathrm{ADH}}{\longrightarrow} \mathrm{CH}_{3} \mathrm{CHO}+\text { hydroquinone }
$$


This behaviour is particularly apparent at slow scan rates $\left(5 \mathrm{mVs}^{-1}\right)$

The measured amperometric current for different concentrations of ethanol using BQ as mediator varied in the range $1-10 \mathrm{mM}$ (figure 2). A straight line was obtained by linear regression analysis and the correlation coefficient $(r)$ was found to be 0.982 $(y=0.20 x+0.02)$. A comparison with literature data will be in order. With $N, N, N^{1}, N^{1}-$ tetramethyl-4 phenylenediamine (TMPD) as a mediator ${ }^{5}$, the linear response was up to $10 \mathrm{nM}$ only. Schumann et al $^{9}$ with their chloranil-pyrrole/pyrrole copolymer report a linear variation with current up to $2 \mathrm{mM}$. At $\mathrm{N}$-methyl phenazinium-tetracyanoquinodimethane (NMP.TCNQ) electrode the linear response could not be stretched beyond $160 \mu \mathrm{M}$ with complete saturation at $8 \mathrm{mM}^{10}$. Thus, the observed response in our system is superior to that reported in the literature. The apparent Michaelis-Menten constant, $K_{m}{ }^{\prime}$ was found to be $12 \mathrm{mM}$. The value is in fair agreement with that calculated from EadieHofstee form, (1), of the Michaelis-Menten equation ${ }^{11,12}$.

$$
j_{s}=j_{\max }-k_{m}^{\prime}\left(j_{s} / C\right)
$$

where $j_{s}$ is the steady state current density, $j_{\max }$ is the maximum current density under saturating substrate conditions and $C$ is the concentration of ethanol in solution. $K_{m}^{\prime}$ was found to be $13.5 \mathrm{mM}$. It may be compared with the $K_{m}$ 'value of $15.4 \mathrm{mM}$ reported using NMPTCNQ electrode ${ }^{10}$.

\subsection{Kinetic aspects}

Quantitative kinetic data for the reaction between the enzyme (ADH) and the mediator (BQ) was obtained according to the methodology of Nicholson and Shain ${ }^{13}$. The theory is suitable for obtaining kinetic information on reactions of the type:

$$
\begin{aligned}
& Z+O \stackrel{k}{\longrightarrow} R, \\
& R-n e^{-} \Leftrightarrow O,
\end{aligned}
$$

where $O$ and $R$ are the respective forms of the mediator and $Z$ is the reduced enzyme.

To study the kinetic aspects, the current function, $i_{\rho} / v^{1 / 2}$ value (table 1$)$ was plotted against $\log v$ (figure 3). The straight line observed for the $\mathrm{BQ} / \mathrm{H}_{2} \mathrm{Q}$ couple is typical for a simple reversible charge transfer process (figure $3 \mathrm{~A}$ ). On addition of ethanol, the variation of current function with $\log v$ was as expected for a catalytically coupled reaction (figure 3B-E). The data were analysed by making use of the working curve (figure 14 of ref. 13) which equates $i_{k} / i_{d}$ (the ratio of kinetic to diffusion controlled current) to the kinetic parameter $\left(k_{f} / a\right)^{1 / 2}$ where $k_{f}$ is the pseudo first order rate constant for the reaction between $\mathrm{ADH}$ and $\mathrm{BQ}$ and $a=n F v / R T$. The $i_{k} / i_{d}$ values were obtained experimentally. The data (table 2) were then plotted for a series of ethanol concentrations between $k / a$ and $1 / \nu$. Under the pseudo first order conditions, the curves should be linear (figure 4). From the slope of each curve which equals $k_{\rho} R T / n F$, scan rate independent pseudo first order rate constant was obtained with $\mathrm{BQ}$ at each of the ethanol concentrations (table 3 ). The $k_{f}$ values were obtained by carrying out the kinetic runs thrice and the uncertainty in these values was estimated to be $\sim 2-3 \%$. They plot of first order rate constant as a function of ethanol concentration was linear (figure 5). From the 


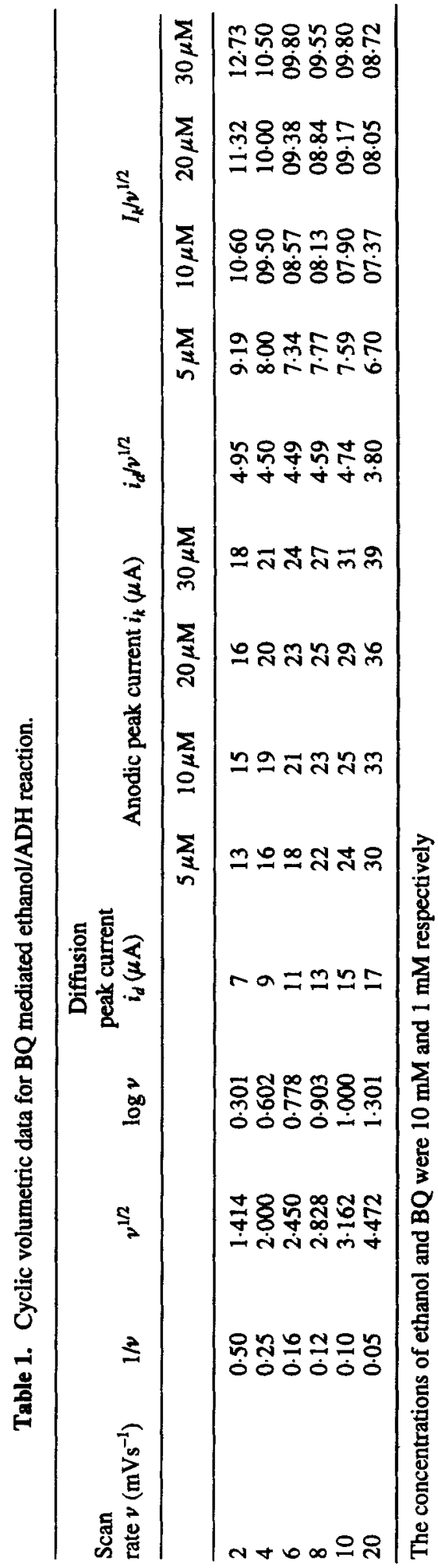




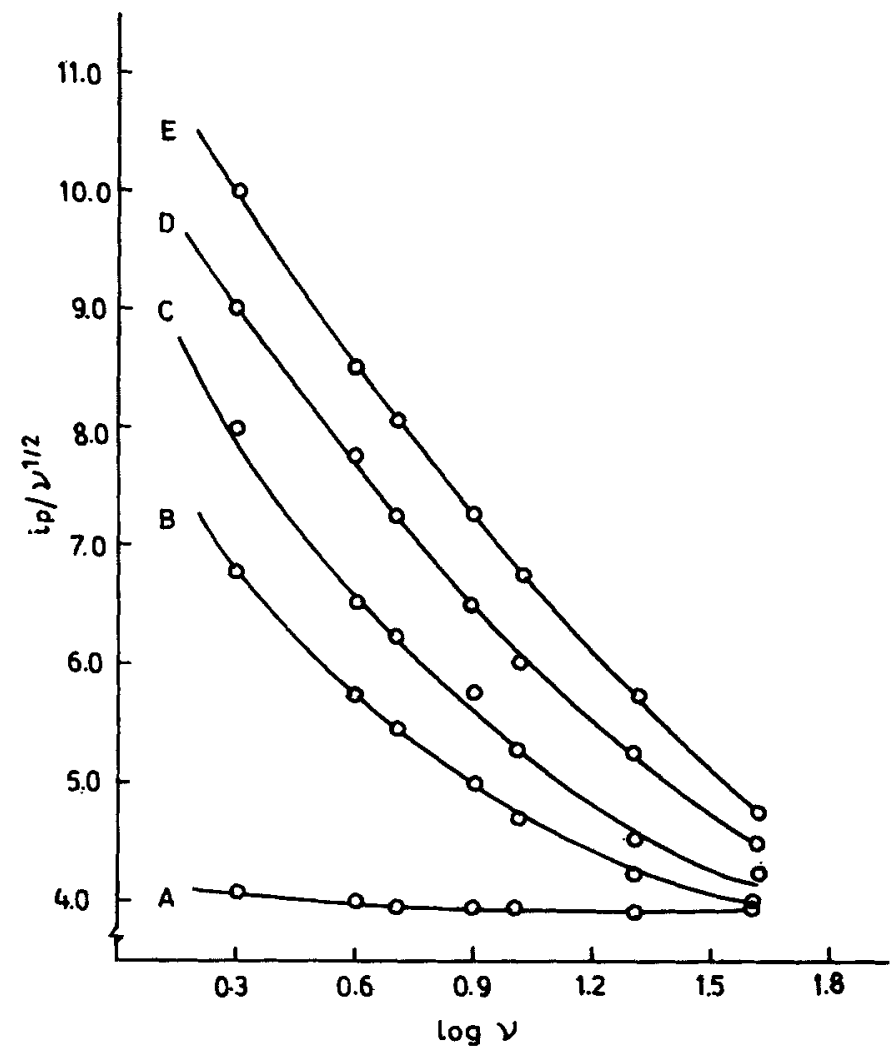

Figure 3. Variation of current function $i_{p} / v^{1 / 2}$ with $\log v$ for (A) diffusion controlled $\mathrm{BQ} / \mathrm{H}_{2} \mathrm{Q}$ redox reaction and for catalytically coupled reaction between $\mathrm{BQ}$ and $\mathrm{ADH}$. The concentrations of ADD are (B) $5 \mu \mathrm{M}$, (C) $10 \mu \mathrm{M}$, (D) $20 \mu \mathrm{M}$, (E) $30 \mu \mathrm{M}$.

slope, $k_{f} /($ ethanol), second order rate constant, for the reaction between ADH and BQ was determined to be $3.8 \times 10^{6} \mathrm{M}^{-1} \mathrm{~s}^{-1}$. In view of the fact that $B Q$ is adsorbed on EPG electrode, the kinetic data should be viewed with caution. This value may be compared with the value $0.6 \times 10^{5} \mathrm{M}^{-1} \mathrm{~s}^{-1}$ obtained for the substrates methanol and other primary alcohols employing ferrcenecarboxylic acid as mediator and $\mathrm{ADH}$ as the enzyme ${ }^{5}$.

Similar observations have been made with FCA as mediator. The measured amperometric current for different concentrations of ethanol using FCA as mediator varied in the range $1-10 \mathrm{mM}$ with a correlation coefficient $(r)$ of 0.989 $(y=0.25 x+0.03)$. The apparent Michaelis-Menten constant, $K_{m}^{\prime}$ was found to be $12 \mathrm{mM}$. The second order rate constant for the reaction between ADH and FCA was calculated to be $1.2 \times 10^{5} \mathrm{M}^{-1} \mathrm{~s}^{-1}$. It can be seen that benzoquinone is an effective mediator for the enzymatic oxidation of ethanol.

The next set of experiments was carried out by immobilizing both $A D H$ and BQ in a PPy matrix.

The cyclic voltammogram of the PPy electrode (containing BQ and ADH) in phosphate buffer displayed the characteristic electrochemistry of BQ as well as catalytic currents upon the addition of ethanol. 
Table 2. Catalytic current data for the $B Q$ mediated ethanol/ADH reaction.

\begin{tabular}{|c|c|c|c|c|c|}
\hline $\begin{array}{l}\text { Conc. of } \\
\mathrm{ADH}(\mu \mathrm{M})\end{array}$ & $\begin{array}{l}\text { Scan rate } \\
\boldsymbol{v}\left(\mathrm{mVs}^{-1}\right)\end{array}$ & $\begin{array}{c}\text { Diffusion } \\
\text { peak current } \\
i_{d}(\mu \mathrm{A})\end{array}$ & $\begin{array}{c}\text { An anodic } \\
\text { peak current } \\
i_{k}(\mu \mathrm{A})\end{array}$ & $i_{k} / i_{d}$ & $k_{f} / a$ \\
\hline 5 & $\begin{array}{r}2 \\
4 \\
6 \\
8 \\
10 \\
20\end{array}$ & $\begin{array}{r}7 \\
9 \\
11 \\
13 \\
15 \\
17\end{array}$ & $\begin{array}{l}13 \\
16 \\
18 \\
22 \\
24 \\
30\end{array}$ & $\begin{array}{l}1.85 \\
1.77 \\
1.63 \\
1.69 \\
1.60 \\
1.76\end{array}$ & $\begin{array}{l}1.21 \\
1.06 \\
1.01 \\
0.95 \\
0.81 \\
0.45\end{array}$ \\
\hline 10 & $\begin{array}{r}2 \\
4 \\
6 \\
8 \\
10 \\
20\end{array}$ & $\begin{array}{r}7 \\
9 \\
11 \\
13 \\
15 \\
17\end{array}$ & $\begin{array}{l}15 \\
19 \\
21 \\
23 \\
25 \\
33\end{array}$ & $\begin{array}{l}2.14 \\
2.11 \\
1.90 \\
1.76 \\
1.66 \\
1.94\end{array}$ & $\begin{array}{l}1.50 \\
1.34 \\
1.23 \\
1.17 \\
1.03 \\
0.85\end{array}$ \\
\hline 20 & $\begin{array}{r}2 \\
4 \\
6 \\
8 \\
10 \\
20\end{array}$ & $\begin{array}{r}7 \\
9 \\
11 \\
13 \\
15 \\
17\end{array}$ & $\begin{array}{l}16 \\
20 \\
23 \\
25 \\
29 \\
36\end{array}$ & $\begin{array}{l}2.28 \\
2.11 \\
2.09 \\
1.92 \\
1.93 \\
2.11\end{array}$ & $\begin{array}{l}1.52 \\
1.36 \\
1.27 \\
1.24 \\
1.09 \\
0.95\end{array}$ \\
\hline 30 & $\begin{array}{r}2 \\
4 \\
6 \\
8 \\
10 \\
20\end{array}$ & $\begin{array}{r}7 \\
9 \\
11 \\
13 \\
15 \\
17\end{array}$ & $\begin{array}{l}18 \\
21 \\
24 \\
27 \\
31 \\
39\end{array}$ & $\begin{array}{l}2.57 \\
2.33 \\
2.18 \\
2.07 \\
2.06 \\
2.29\end{array}$ & $\begin{array}{l}1.84 \\
1.68 \\
1.55 \\
1.49 \\
1.37 \\
1.18\end{array}$ \\
\hline
\end{tabular}

The concentrations of ethanol and $B Q$ were $10 \mathrm{mM}$ and $1 \mathrm{mM}$ respectively

Table 3. Kinetic data for the reaction between reduced ADH and BQ

\begin{tabular}{lll}
\hline Conc. of ADH $(\mu \mathrm{M})$ & $k_{f}\left(\mathrm{~s}^{-1}\right)$ & $k\left(\mathrm{M}^{-1} \mathrm{~s}^{-1}\right)$ \\
\hline 5 & 0.662 & \\
10 & 1.450 & $3.8 \times 10^{6}$ \\
20 & 2.750 & \\
30 & 3.520 & \\
\hline
\end{tabular}

The measured amperometric current for different concentrations of ethanol varied in the range 1-8 $\mathrm{mM}$. A straight line was obtained by linear regression analysis and the correlation coefficient $(r)$ was found to be $0.988[y=0.4 x+0.045]$. The apparent Michaelis-Menten constant, $K_{m}^{\prime}$ was found to be $9 \mathrm{mM}$. The immobilized configuration will have restrictions of diffusion of the analyte within the polymer film and this should increase the linear range compared to what was observed in the immobilized state. It is difficult to rationalize this observation in view of the uncertainty in the pore size of the membrane vis-a-vis the analyte size. 


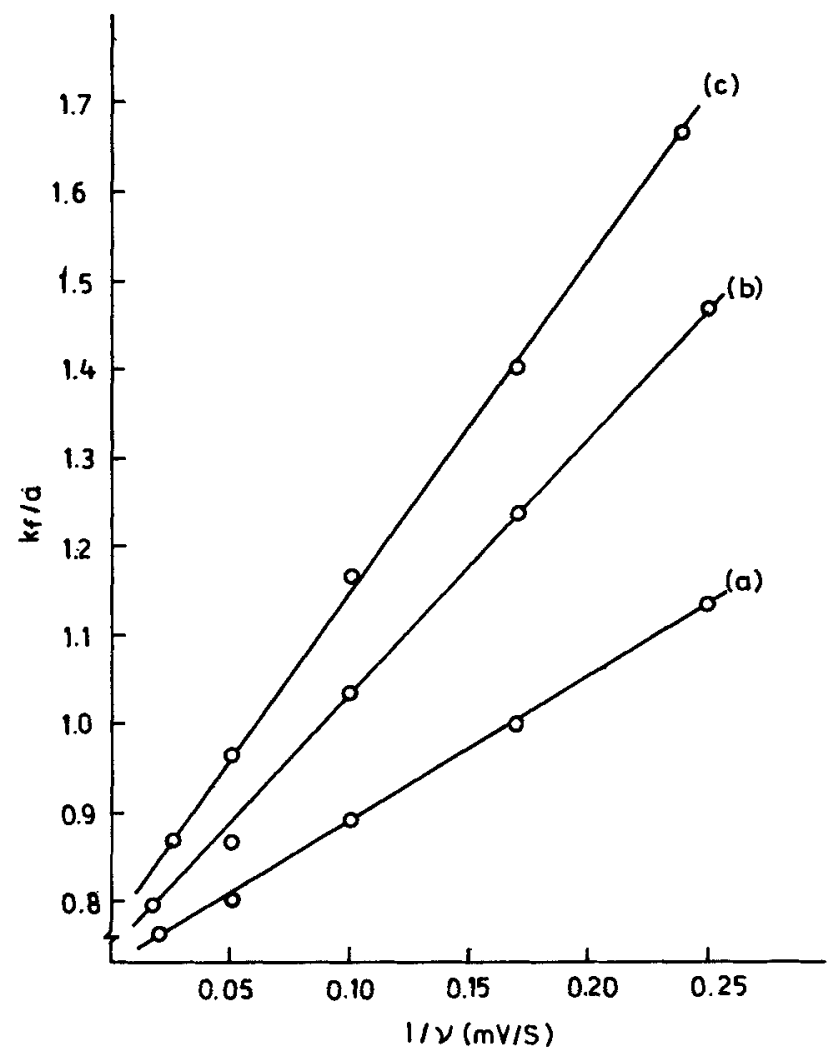

Figure 4. The kinetic parameter, $k / a$, as a function of $1 / v$ for various $A D H$ concentrations: (a) $10 \mu \mathrm{M}$, (b) $20 \mu \mathrm{M}$, (c) $30 \mu \mathrm{M}$.

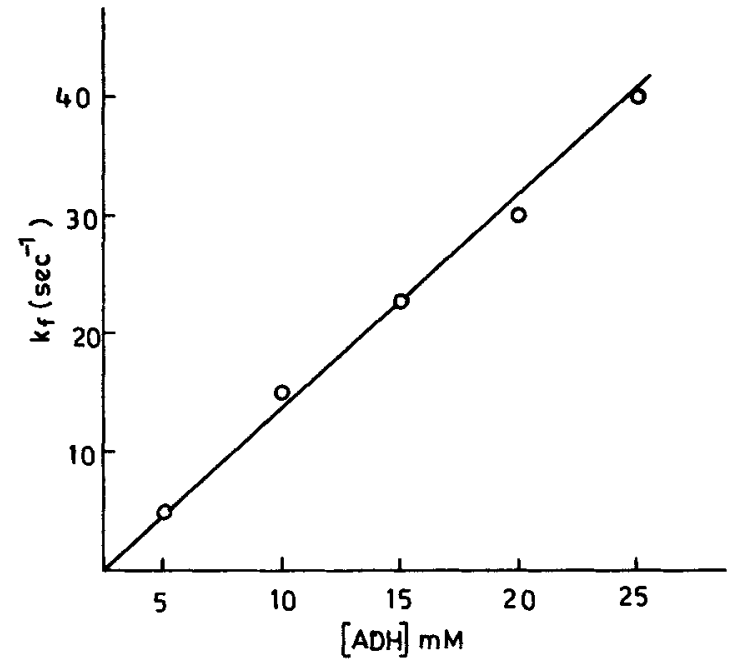

Figure 5. Plot of first order rate constant as a function of $\mathrm{ADH}$ concentration. 


\section{Conclusions}

It is interesting that BQ and FCA act as effective mediators in the electrooxidation of ethanol using a quinoprotein ADH. The variation of the amperometric current along with the kinetic data demonstrate that this enzyme-catalysed reaction could be effectively employed for the development of a sensor for ethanol. The immobilization methodology described using PPy, holds a promise for the commercial development of an ethanol sensor.

\section{References}

1. Tumer A P F (ed.) 1991, 1992 In Advances in biosensors (London: Jai) vols 1 and 2

2. Duine J A and Frank J 1981 Trends Biochem. Sci. 6278

3. Ghosh R and Quale J R 1981 Biochem. J. 199245

4. Davis G, Hill H A O, Aston W J, Higgins I J and Turner A P F 1983 Enzyme Microb. Technol. 5383.

5. Cass A E G, Davis G, Green M J and Hill H A O 1985 J. Electroanal. Chem. 190177

6. Murthy A S N and Sharma J 1997 Proc. Indian Acad. Sci. (Chem. Sci.) 109 295; Murthy A S N and Sharma J 1997 Talanta 45 951; Murthy A S N and Sharma J 1997 Electroanalysis 9 726; Murthy A S N and Sharma J 1998 Anal. Chem. Acta 363 215; Murthy A S N and Sharma J 1999 Electroanalysis 11188

7. Ikeda T, Kobayashi D, Matsushita F, Sagara T and Miki K 1993 J. Electroanal. Chem. 361 221

8. Yabuki S, Shinohara H, Ikariyama Y and Aizawa Z 1990 J. Electroanal. Chem. 277179

9. Schuhmann W, Lammert R, Hammerle M and Schmidt H-L 1991 Biosensors Bioelectron. 6 689

10. Bartlett P N 1990 In Biosensors - A practical approach (ed) A E G Cass (Oxford: IRL Press)

11. Castner J F and Wingard L B 1984 Biochemistry 232203

12. Gregg B A and Heller A 1990 Anal. Chem. 62258

13. Nicholson S and Shain I 1964 Anal. Chem. 36706 